\title{
Asbestos and lung cancer in Glasgow and the west of Scotland
}

\author{
Helene De Vos Irvine, Douglas W Lamont, David J Hole, Charles R Gillis
}

\begin{abstract}
Objective-To quantify the relation between lung cancer and exposure to asbestos in men in west Scotland and to estimate the proportion of lung cancer which may be attributed to exposure to asbestos.
\end{abstract}

Design-An ecological correlation study of the incidence of lung cancer in men and past asbestos exposure. The unit of analysis was the postcode sector. Correction was made for past cigarette smoking, air pollution, and deprivation.

Setting-The region covered by the west of Scotland cancer registry, containing 2.72 million people and including Glasgow and the lower reaches of the River Clyde, where shipbuilding was once a major industry.

Subjects-All men diagnosed with lung cancer between 1975 and 1984 whose residence at the time of registration was within the west of Scotland.

Main outcome measure-The population attributable risk for asbestos related lung cancer.

Results-An estimated $5 \cdot 7 \% \quad(95 \%$ confidence interval 2.3 to $9 \cdot 1 \%$ ) of all lung cancers in men registered in the west of Scotland during the period 1975-84 were asbestos related, amounting to 1081 cases.

Conclusions-A considerable proportion of cases of lung cancer in men in Glasgow and the west of Scotland from 1975 to 1984 were asbestos related. Most of these may not have been considered for compensation by the Department of Social Security. Given the very small annual number of recorded cases of asbestosis this condition is probably not a prerequisite for the development of asbestos related lung cancer. A heightened awareness of the increasing incidence of asbestos related neoplasms and their more thorough investigation are recommended.

\section{Introduction}

A comparison of international cancer registry data shows that the west of Scotland experiences one of the highest incidence rates of lung cancer in the world.' Within this area rates are far from equally distributed, the highest occurring in Glasgow (128.5 per 100000 per year world standardised for 1981-90). Three other areas in the west of Scotland known for their history of shipbuilding or heavy industry and construction (Clydebank, Renfrew, and Inverclyde) have rates in excess of the average for the west of Scotland for the same period.

Male smokers locally experience twice the rate of death from lung cancer for the same amount of cigarettes smoked compared with three other cohorts, ${ }^{2}$ suggesting an additional causal factor operating in the west of Scotland. Passive smoking was shown to be an unlikely cause of the excess. ${ }^{3}$

Asbestos related lung cancer is thought to be numerically and proportionately the most important occupational cancer in the world. ${ }^{4}$ Attention was focused on occupational exposure to asbestos as a suspected factor in the west of Scotland by a validation and exposure study conducted in the catchment area for Greater Glasgow health board, which showed high incidence rates of mesothelioma in Glasgow and Clydebank during the period 1981-3.

\section{BACKGROUND}

The River Clyde from Glasgow to Greenock was a major shipbuilding centre for more than 200 years. Asbestos fibres of all types, including crocidolite, ${ }^{6}$ were used for insulation in the shipbuilding industry, especially during the second world war. ${ }^{7}$ Census data from 1931, 1951, and 1961 show that substantial proportions (ranging from $8 \%$ to $61 \%$ ) of the male workforce were employed in the shipyards of west of Scotland districts. ${ }^{8}$ Asbestos was also used to insulate gasworks, locomotives, and homes and factories throughout the central Clydeside conurbation.

Per head the United Kingdom imported more crocidolite and amosite from South Africa than did any other country in the world between 1945 and $1963 .{ }^{9}$ Within the United Kingdom a national study of death rates for mesothelioma by region produced by the Health and Safety Executive showed the crude rate to be highest in the north of England (58.5 per million men during 1987-9) closely followed by that for the west of Scotland (57.6 per million). ${ }^{10}$ The secular trend in the age standardised incidence of mesothelioma for the west of Scotland showed a steady increase culminating in a rate for 1989 of 66 per million (95\% confidence interval 54 to 81 ; fig 1 ). Within the west of Scotland the incidence of mesothelioma by local government district varied considerably with high rates again seen where shipbuilding, heavy industry, and construction were common. The highest rates were found in Clydebank, where the age standardised incidence of mesothelioma in men has exceeded that of stomach cancer (the fifth commonest cancer) since 1986 and was on a par with that of colorectal cancer in 1989 , when the rate reached 512 per million $(95 \%$ confidence interval 265 to 896 ; fig 1 ).

Given that the prevalence of smoking among men in Glasgow has generally been high ${ }^{112}$ and a sizable proportion of working men were exposed to asbestos it was considered that the synergistic relation ${ }^{13-15}$ between these two risk factors could be responsible for higher rates of lung cancer than those seen in countries where the prevalence of smoking was higher than in Glasgow. ${ }^{16}$

We report the results of a study designed to quantify the relation between lung cancer and past exposure to asbestos while correcting for the confounding variables of smoking and air pollution and to estimate the proportion of all lung cancer in men which is asbestos related. 


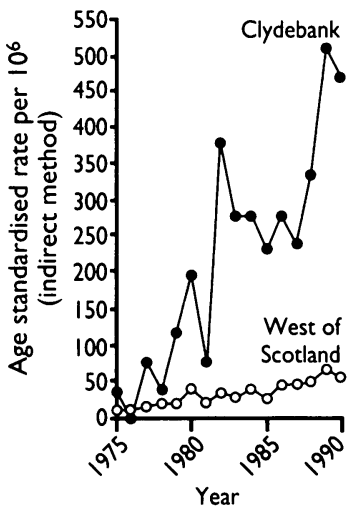

FIG 1-Incidence of mesothelioma in men, 1975-90. Figures based on registrations received by 15 December 1991 by west of Scotland cancer registry

\section{Subjects and methods}

The subjects of study were all men living in the west of Scotland who were diagnosed with lung cancer between 1975 and 1984. The unit of analysis was the postcode sector. Data on the incidence of cancer were obtained from the west of Scotland cancer registry. The age standardised incidence of lung cancer (ICD (ninth revision) code 162) in men was calculated for 1975-84. This period was chosen to encompass the expected peak in asbestos related lung cancer, for which the latency period tends to be less than 30 years after exposure. ${ }^{13}$

The age standardised incidence of mesothelioma (ICDO codes 9050-9054) in men for the period 1980-9 was used as a proxy for past exposure to asbestos of all fibre types. This later period was chosen to take into consideration the fact that the latency period for mesothelioma, ranging from 30 to 50 years, is longer than that for asbestos related lung cancer. Age specific incidence rates for the west of Scotland were used to indirectly standardise these data.

Past cigarette smoking was measured by mortality from chronic bronchitis (ICD codes 490-1, 492, 496), a strong correlate of the prevalence of smoking. ${ }^{17}$ These data were obtained from the registrar general for Scotland for the period 1975-84. Age specific mortality for Scotland was used to indirectly standardise these data.

Counts of average smoke concentrations $\left(\mu \mathrm{g} / \mathrm{m}^{3}\right)$ in winter for 53 measuring stations throughout the region during 1960-1 (before the Clean Air Act 1956 had time to come into effect ${ }^{18}$ were used to assign an approximate measure of air pollution to all 456 postcode sectors. A measure of deprivation, based on male unemployment, overcrowding, low social class, and lack of a car, ${ }^{17}$ was used to take account of other potential risk factors related to lung cancer-for example, hypovitaminosis $A$ and $\left.\mathrm{E}^{19}{ }^{20}\right)$.

A weighted stepwise multiple linear regression analysis was conducted of the linear dependence of incidence of lung cancer on incidence of mesothelioma while correcting for past cigarette smoking, air pollution, and deprivation. Because of a high degree of positive skew the distribution of mesothelioma rates was $\log$ transformed. The inverse of the standard error of the incidence rate for lung cancer for each postcode sector was used as a weighting factor. The 104 postcode sectors with populations of fewer than 1500 men were excluded from the study.

In the absence of a direct estimate of the prevalence of asbestos exposure in the population the population attributable risk (PAR) for asbestos related lung cancer was calculated as: $\mathrm{PAR}=$ incidence of asbestos related lung cancer in the west of Scotland (1975-84)/incidence of all lung cancer in the west of Scotland 1975-84x $100 \%$.

The incidence of asbestos related lung cancer in 1975-84 was derived from the regression equation by multiplying the regression coefficient for mesothelioma by the log transformed incidence rate for mesothelioma for all of the west of Scotland for 1980-9.

\section{Results}

The incidence of lung cancer varied from 32 per

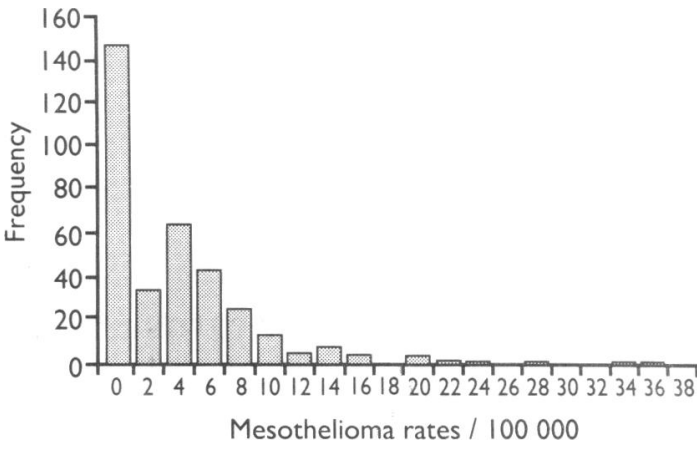

FIG 2-Frequency distribution of incidence rates for mesothelioma standardised for age for each postcode sector. No=382, excluding sectors with population $<1500$

100000 per year to 333 per 100000 per year (table I) and was significantly correlated with each of the four independent variables (table II). No cases of mesothelioma were recorded in 148 postcode sectors $(42 \%)$ while 25 sectors $(7 \%)$ had rates greater than 10 per 100000 per year (fig 2).

Stepwise multiple regression showed all four unstandardised regression coefficients to be significantly different from zero (table III). Over $70 \%$ of the variation in the incidence rates of lung cancer was accounted for by the four independent variables in the model, with the major explanatory variable, the proxy for cigarette smoking, accounting for $54 \%$. The regression coefficient for the logarithm of mesothelioma incidence was $11.545(\mathrm{p}<0.01)$, implying an increase of 11.545 in the incidence of lung cancer per 100000 men for every unit change in the log transformed mesothelioma rate per 100000 . The population attributable risk for asbestos related lung cancer for the period 1975-84 was calculated as follows, amounting to $5 \cdot 7 \%$ (1081 cases) over the period of the study:

$\mathrm{PAR}=11 \cdot 545\left(\log 3 \cdot 80^{\star}\right.$ per $\left.100000+1\right) / 138 \cdot 5$ per $100000 \times 100 \%$

$$
=7 \cdot 86 / 138 \cdot 5 \times 100 \%=5 \cdot 7 \%
$$

*Assuming that the "environmental" baseline mesothelioma rate of 2 per million per year ${ }^{21}$ applies, thereby reducing the mesothelioma rate for the west of Scotland attributable to asbestos exposure to 3.8 per 100000 from 4.0 per 100000 per year.

The directly age standardised rates of 4.0 per 100000 for mesothelioma and 138.5 per 100000 for lung cancer were used in preference to the sample means because of their much smaller standard errors $(0.2$ and $1 \cdot 0$, respectively). The $95 \%$ confidence interval for the population attributable risk was calculated by using the confidence limits for the unstandardised regression coefficient of 4.63 to 18.46 (table III) as $2 \cdot 3 \%$ to $9 \cdot 1 \%$ (equivalent to between 436 and 1725 cases).

\section{Discussion}

Our study suggests that as much as $6 \%$ of lung cancer in men in the west of Scotland between 1975 and 1984 may be attributable to exposure to asbestos. The risk of "ecological fallacy" accounting for this correlation

TABLE I-Descriptive statistics for variables used in the regression analysis of incidence of lung cancer and mesothelioma in men in Glasgow and the west of Scotland

\begin{tabular}{|c|c|c|c|c|c|}
\hline & Mean & SD & Median & Minimum & Maximum \\
\hline Incidence rate of lung cancer per 100000 men per year & 133.787 & $49 \cdot 871$ & $121 \cdot 896$ & 31.833 & $333 \cdot 370$ \\
\hline Incidence rate of mesothelioma per 100000 men per year & 3.824 & $5 \cdot 100$ & 2.601 & 0.000 & 36.060 \\
\hline Log of mesothelioma incidence rate +1 & 0.471 & 0.438 & 0.556 & 0.000 & 1.569 \\
\hline Mortality from chronic bronchitis per 100000 men per year & 78.037 & $37 \cdot 176$ & 71.999 & $12 \cdot 153$ & 257.739 \\
\hline Air pollution (smoke $\left.\mu \mathrm{g} / \mathrm{m}^{3}\right)$ & $201 \cdot 889$ & $95 \cdot 867$ & $191 \cdot 000$ & $50 \cdot 000$ & $540 \cdot 000$ \\
\hline Deprivation score & 0.626 & 3.874 & 0.215 & $-7 \cdot 310$ & $12 \cdot 270$ \\
\hline
\end{tabular}


TABLE II-Matrix of correlation coefficients * for variables used in the regression analysis

\begin{tabular}{lcccc}
\hline & $\begin{array}{c}\text { Incidence rate for } \\
\text { mesothelioma } \\
\text { (log transformed) }\end{array}$ & $\begin{array}{c}\text { Deprivation } \\
\text { score }\end{array}$ & $\begin{array}{c}\text { Mortality from } \\
\text { chronic } \\
\text { bronchitis }\end{array}$ & $\begin{array}{c}\text { Air } \\
\text { pollution }\end{array}$ \\
\hline $\begin{array}{l}\text { Incidence rate of lung cancer } \\
\text { Incidence rate of mesothelioma } \\
\text { (log transform) }\end{array}$ & 0.327 & 0.731 & 0.736 & 0.628 \\
$\begin{array}{l}\text { Deprivation score } \\
\text { Mortality from chronic bronchitis }\end{array}$ & & $\begin{array}{c}0.151 \\
(\mathrm{p}<0.01)\end{array}$ & $\begin{array}{c}0.149 \\
(\mathrm{p}<0.01) \\
0.739\end{array}$ & 0.443 \\
& & & & 0.436 \\
\end{tabular}

^All correlation coefficients significant at $p<0.001$ except where shown

TABLE III-Results of stepwise multiple regression analysis

\begin{tabular}{|c|c|c|c|c|c|c|}
\hline Variable & $\begin{array}{l}\text { Regression } \\
\text { coefficient }\end{array}$ & SE & $\begin{array}{l}95 \% \text { Confidence } \\
\text { interval for } \\
\text { regression } \\
\text { coefficient }\end{array}$ & $\mathrm{t}$ & $\mathrm{p}$ Value & $\underset{\mathrm{R}^{2}}{\text { Multiple }}$ \\
\hline Chronic bronchitis & 0.441 & 0.063 & 0.318 to 0.565 & $7 \cdot 03$ & $<0.001$ & $0 \cdot 542$ \\
\hline Air pollution & $0 \cdot 132$ & 0.019 & 0.095 to 0.169 & 6.98 & $<0.001$ & 0.633 \\
\hline Deprivation score & 4.584 & 0.552 & 3.498 to 5.670 & $8 \cdot 30$ & $<0.001$ & 0.693 \\
\hline Mesothelioma (log transformed) & 11.545 & $3 \cdot 517$ & $4 \cdot 628$ to $18 \cdot 462$ & $3 \cdot 28$ & $<0.01$ & 0.702 \\
\hline Constant & $61 \cdot 726$ & & & & & \\
\hline
\end{tabular}

is minimal because, firstly, the relation between exposure to asbestos and the risk of lung cancer is well known and causal; secondly, a range of independent variables was chosen to represent all the known risk factors for this disease ${ }^{22}$; and, thirdly, it is most unlikely that an unconsidered confounder exists at the level of postcode sector that is associated both with mesothelioma and with lung cancer.

The reliability of the method is increased by the large number of postcode sectors (and therefore high statistical power), by aggregating over a 10 year period, by using only those postcode sectors where the population of men was over 1500 , by weighting the postcode sectors in favour of larger populations, and by the large numbers of cases-18958 registrations of lung cancer and 546 registrations of mesothelioma. Because the percentage of cases histologically verified was much higher for mesothelioma $(80 \%)$ than for lung cancer $(46 \%)$ the possibility of misdiagnosis of mesothelioma as lung cancer would serve to weaken a real correlation rather than create a spurious one, thereby supporting our hypothesis.

Estimates of the extent of asbestos related lung cancer are based largely on data from America. A dozen studies attempted to quantify occupational cancer after publication of the controversial paper by Bridbord et al (the "OSHA" paper). ${ }^{23}$ Several of these studies $^{42-26}$ provided estimates for asbestos related lung cancer in the range of $1-5 \%$, while that of Doll and Peto, ${ }^{4}$ at $5 \%$, closely approximates the point estimate in our study. This was based on the American population in the early $1970 \mathrm{~s}$, when the mesothelioma rate was only 7 per million and the expected peak was still far off (note the west of Scotland rate of 66 per million for 1989). Previous studies have shown that between one and 10 cases of asbestos related lung cancer occur for every mesothelioma in an exposed cohort. ${ }^{4}$ In the west of Scotland, where 546 cases of mesothelioma occurred between 1980 and 1989, we could expect to see on this basis between 546 and 5460 cases of asbestos related lung cancers. Our independent estimate of 1081 is at the lower end of this range and therefore may be a conservative estimate. As underdiagnosis of mesothelioma is likely to have occurred to a varying degree it would seem reasonable to conclude that at least $5 \%$ of all lung cancers registered in the west of Scotland between 1975 and 1984 were asbestos related. Further study on a retrospective or prospective basis would be necessary to confirm this estimate.

Central to our hypothesis is the nature of the doseresponse relation for the various asbestos related diseases. It has generally been accepted that the development of asbestosis follows heavy long term exposure and shows a threshold level. For the asbestos related neoplasms roughly linear dose-response curves are thought to exist with no threshold,${ }^{13}$ suggesting that even very low or short term exposure to asbestos may cause lung cancer (all fibre types) or mesothelioma (crocidolite) without $x$ ray evidence of pulmonary fibrosis. ${ }^{101328-34}$ A few authors, however, believe that heavier and longer term exposures are required for the development of lung cancer than for mesothelioma and that the development of fibrosis (asbestosis) is a prerequisite for asbestos related lung cancer. ${ }^{722} 27336$

The Health and Safety Executive estimates that for every one of the 800 registered cases of mesothelioma seen annually in Great Britain, two cases of asbestos related lung cancer occur. Our estimate of 1081 asbestos related lung cancers per 546 mesothelioma registrations closely agrees with this ratio. This contrasts clearly with the 59 awards to victims of asbestos related lung cancer made in $1988 .{ }^{37}$

The respiratory diseases section of the Medical Boarding Centre maintains that lung cancer in a man with a definite history of occupational exposure to asbestos is not a prescribed disease (and therefore not liable for compensation) unless accompanied by either asbestosis or bilateral diffuse pleural thickening.

Clearly most cases do not receive compensation. For this to improve it is at the very least essential that a full occupational history is taken from any man with lung cancer who was in employment during the second world war or until 1969, when the asbestos regulations came into being. Those patients with a positive occupational history should be considered for open lung biopsy to measure the number of asbestos bodies or, better still, the number of amosite and crocidolite fibres per gram of dry lung tissue. Reference ranges set by consensus on the basis of laboratory data $a^{3033}$ could then be applied to estimate the likelihood that the lung tumour is due to asbestos.

1 Muir C, Waterhouse J, Mack T, Powell J, Whelan S, eds. Cancer incidence in five continents. Vol V. Lyon: IARC, 1987. (IARC Scientific Publications No 88.)

2 Gillis CR, Hole DJ, Hawthorne VM. Cigarette smoking and male lung cancer in an area of very high incidence. II. Report of a general population cohor study in the west of Scotland. I Epidemiol Community Health 1988;42:44-8.

3 Hole DJ, Gillis CR, Chopra C, Hawthorne VM. Passive smoking and cardiorespiratory health in a general population in the west of Scotland BMF 1989;299:423-7.

4 Doll R, Peto R. The causes of cancer. Oxford: Oxford Medical Publications, 1981:1238-45. (Appendix F:1305-8.)

5 Gillis CR, Hole DJ, Lamont DW. Incidence of mesothelioma in Glasgow 1981 1984. I Soc Occup Med 1990;40:5-10.

6 Dorward AJ, Stack HR. Diffuse malignant pleural mesothelioma in Glasgow. British fournal of Diseases of the Chest 1981;75:397.

7 Murray R. Asbestos: a chronology of its origins and health effects. Br f Ind Med 1990;47(6):361-5.

8 Office of Population Censuses and Surveys. 1951 Census for Scotland. Edinburgh: HMSO, 1951

9 May TC. Statistical tables-asbestos. Appendix 3. In: Whipple HE, Van Reyen PE, eds. Biological effects of asbestos. Ann N Y Acad Sci 1965;132:745-65.

10 Health and Safety Executive, Department of Employment. Health and safety statistics 1989-90. London: HSE, DoE 1991;99(9):72-3.

11 World Health Organisation. The MONICA project. World Health Statistics Quarterly 1988;41:115-37.

12 Tunstall-Pedoe H, Smith WCS, Crombie IK, Tavendale R. Coronary risk factor and lifestyle variation across Scotland: results from the Scottish hear health study. Scot Med f 1989;34:556-60.

13 Doll R, Peto J. Asbestos: effects on health of exposure to asbestos. London: Health and Safety Commission, HMSO, 1985.

14 Hammond EC, Selikoff IJ, Seidman H. Asbestos exposure, cigarette smokin and death rates. Ann N Y Acad Sci 1979;330:473-90.

15 Selikoff IJ, Hammond EC, Churg J. Asbestos exposure, smoking an neoplasia. IAMA 1968;204:104-10.

16 Stjernsward J, Stanley K. Lung cancer-a worldwide health problem. In: Joss RA, Brunner KW, eds. Lung cancer. Fournal of International Association of Study of Lung Cancer 1988;4:11-24.

17 Carstairs V, Morris R. Deprivation and health in Scotland. Aberdeen: Aberdeen University Press, 1991.

18 Warren Spring Laboratory. National survey of air pollution 1961-1971. Vol 5. London: Department of Industry, HMSO, 1976.

19 Fulton M, Thomson M, Elton RA, Brown S, Wood DA, Oliver MS. Cigarette smoking, social class and nutrient intake: relevance to coronary arter disease. European fournal of Chemistry and Nutrition 1988;42:797-803

20 Seaton A, Seaton D, Leitch AG. Crofton and Douglas's respiratory diseases. 4th ed. Oxford: Blackwell Scientific Publications, 1988.

21 Doll R. Mineral fibres in the non-occupational environment: concluding remarks. In: Bignon J, Peto J, Saracci R, eds. Non-occupational exposures 
mineral fibres. Lyons: International Agency for Research on Cancer, 1989:511-8. (IARC Scientific Publications No 90.)

22 Fraser G, Pare JAP, Pare PD, Fraser RS, Genereux GP. Diagnosis of diseases of the chest. Vol II 3rd ed. New York: Saunders, 1989.

23 Bridbord K, Decoufle P, Fraumeni JF Jr, Hoel DG, Hoover RN, Rall DP, et al. Estimates of the fraction of cancer in the United States relat DP, al. Estmated to occupational factors. In: Peto R, Schneiderman M, eds. Quantification of occupational cancer. New York:

24 Peto J, Henderson BE, Pike MC. Trends in mesothelioma incidence in the United States and the forecast epidemic due to asbestos exposure during WWII. In: Peto R, Schneiderman M, eds. Quantification of occupational cancer. New York: Cold Spring Harbor Laboratory, 1981:51-72. (Banbury report No 9.)

25 Enterline PE. Proportion of cancer due to exposure to asbestos. In: Peto R, Schneiderman M, eds. Quantification of occupational cancer. New York: Cold Spring Harbor Laboratory, 1981:19-36. (Banbury report No 9.)

26 Higginson J, Bahar JC, Clemmesen J, Demopoulos H, Garfinkel L, Hirayama T, et al. Proportion of cancers due to occupations. Prev Med 1980;9:180.

27 Parkes WR. Occupational lung disorders. 2nd ed. London: Butterworth, 1982.

28 Selikoff IJ, Churg J, Hammond EC. Asbestos exposure and neoplasia. \AMA 1964;188:22-6.
29 Martischnio KM, Newall DJ, Barnsley WC, Cowan WK, Feinmann EL Oliver $\mathrm{E}$. Unsuspected exposure to asbestos and bronchogenic carcinom BMF 1977; ; 746 .

30 Warnock ML, Isenberg W. Asbestos burden and the pathology of lung cancer Chest 1986;89:20.

31 Mancuso TF, Coulter EJ. Methodology in industrial health studies. Arch Environ Health 1963;6:210-26.

32 Sluis-Cremer GK. The relationship between asbestosis and bronchial cancer. Chest 1980;78 (suppl 2):380-1.

33 Roggli VL, Pratt PC, Brody AR. Asbestos content of lung tissue in asbestos associated diseases: a study of 110 cases. Br I Ind Med 1986;43:18-28.

34 Kipen HM, Lilis R, Suzuki Y, Valciukas JA, Selikoff IJ. Pulmonary fibrosis in asbestos insulation workers with lung cancer: a radiological and histopathological evaluation. Brf Ind Med 1987;44:96-100.

35 Hughes JM, Weill $\mathrm{H}$. Asbestosis as a precursor of asbestos-related lung cancer: results of a prospective mortality study. Br f Ind Med 1991;48:229-33.

36 Daniel FB. In vitro assessment of asbestos genotoxicity. Environ Health Perspect 1983;53:163-7.

37 Department of Social Security. Social security statistics 1989. London: HMSO, 1989.

(Accepted 8 April 1993)

\title{
A prospective study of alcohol consumption and bone mineral density
}

\author{
Troy L Holbrook, Elizabeth Barrett-Connor
}

\begin{abstract}
Objectives-To study the effects of alcohol consumption on bone mineral density in a defined population.
\end{abstract}

Design-Prospective study of bone mineral density, measured during 1988-91, in a cohort who had given baseline data on alcohol intake in the previous week and in the previous 24 hours and other factors affecting bone mineral density during 1973-5.

Setting-Rancho Bernardo, California.

Subjects -182 men and 267 women aged 45 and over at baseline, half having been randomly selected and half having been chosen for hyperlipidaemia, who gave baseline information on alcohol intake in one week. Of these subjects, 142 men and 220 women gave information on alcohol intake in 24 hours.

Main outcome measures-Bone mineral density of the radial shaft, ultradistal wrist, femoral neck, and lumbar spine.

Results-Men and women were considered separately, and the tertiles of alcohol consumption were used to delineate low, medium, and high values of alcohol intake. With increasing alcohol intake in one week, bone mineral density (adjusted for age, body mass index, smoking, taking exercise, and oestrogen replacement therapy in women) increased significantly in the femoral neck of men $(p<0.01)$ and the spine of women $(p<0.01)$. With increasing alcohol intake in 24 hours, adjusted bone mineral density increased significantly in the radial shaft $(p<0.05)$ and spine $(p<0.001)$ of women. Similar, but not significant, patterns were seen at the other bone sites.

Conclusions-Social drinking is associated with

Department of Community and Family Medicine, University of California, San Diego, La Jolla, CA 92093, USA

Troy L Holbrook, assistant adjunct professor Elizabeth Barrett-Connor, professor and chair

Correspondence to:

Professor Holbrook.

$B M \mp$ 1993;306:1506-9

\section{higher bone mineral density in men and women.}

\section{Introduction}

Osteoporosis is a leading cause of morbidity and disability among elderly populations in Western countries and is the most important underlying cause of fractures of the hip, spine, distal wrist, and humerus in elderly people. A higher body mass index is an established protective factor for osteoporosis, and recent evidence indicates that diet, smoking, exercise, and use of drugs may be important in the aetiology of this disease. ${ }^{1}$
Several studies have shown that alcohol consumption is also associated with osteoporosis and osteoporotic fractures, ${ }^{2-8}$ although most of these studies were on chronic alcoholics, who may have been seriously malnourished and more likely to fall. Alcohol is directly toxic to bone and may disrupt bone metabolism. ${ }^{10}$ Several recent reports, however, have suggested that alcohol consumption may be associated with higher bone mineral density in postmenopausal women, ${ }^{11-13}$ although others did not find this association. ${ }^{14}$ is All these reports were limited to women, and most were based on small numbers of volunteers, were cross-sectional, and did not control for other factors associated with bone mineral density. We describe a prospective study of the association of alcohol consumption with bone mineral density in a defined population of men and women.

\section{Subjects and methods}

During $1972-482 \%$ of all adult residents of a geographically defined, upper middle class, white community in Rancho Bernardo, California, participated in a survey of risk factors for heart disease. ${ }^{10}$ During 1973-5 30\% of this cohort were invited for a second, more extensive examination. Half of this group were randomly sampled from the original participants and the rest were all the hyperlipidaemic subjects from the original cohort (defined as those whose plasma cholesterol or triglyceride concentrations were at or above the age and sex specific 90th centiles for cholesterol or 95th centiles for triglycerides, or those who were taking lipid lowering drugs). Of those invited, $92 \%$ attended the clinic. The randomly selected and hyperlipidaemic subjects did not differ significantly with respect to diet or alcohol intake and were combined for this analysis, which used baseline data obtained during 1973-5.

The baseline data included information on cigarette smoking and drugs taken, including diuretics and oestrogen replacement therapy, obtained with standard questionnaires administered by interviewers; height and weight measured with the subjects in light clothing and without shoes; obesity estimated from the body mass index (weight $(\mathrm{kg}) /\left(\right.$ height $\left.(\mathrm{m})^{2}\right)$; and plasma aspartate aminotransferase activity determined by a modification of Karmen's method. ${ }^{17}$ Alcohol intake was based on two interviews: the reported average 